An Analysis of Infant Mortality Rates in the U.S.

by

Paul M. Sommers

July 2003

MID D LEBURY COLLEGE ECONO MICS D ISCUSSION PAPER NO . 03-16

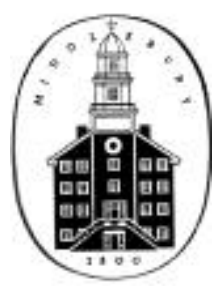

DEPARTMENT OF ECONOMICS

MIDDLEBURY COLLEGE

MIDD LEBURY, VERMO NT 05753

http:/ / www.middlebury.edu/ econ 
AN ANALYSIS OF INFANT MORTALITY RATES IN THE U.S.

by

Paul M. Sommers

Department of Economics

Middlebury College

Middlebury, Vermont 05753

JEL \#: I12 


\section{AN ANALYSIS OF INFANT MORTALITY RATES IN THE U.S.}

For individual groups and nations, there is abundant evidence of a strong quantitative association between measures of economic status and a variety of health outcomes, such as mortality and morbidity [see, for example, J.P. Smith, Journal of Economic Perspectives, Spring 1999]. When the reference group is a U.S. state, economic resources and health risk behaviors such as smoking are no less important predictors of infant mortality rates (defined as the number of deaths in the first year of life compared with the number of live births).

A regression of 50 statewide average infant mortality rates (IMR) [Health, United States, 2002, Table 24] against the same three-year average (1998-2000) percent of people in poverty by state (POV) [Poverty in the United States:2000, Table D], the percentage of women who smoke cigarettes in each state (SMOKERS), the percentage of African Americans by state (BLACK) [Statistical Abstract of the United States: 2002, Tables 185 and 22, respectively], and three dummy variables employed to capture regional differences produced the following results:

$$
\begin{aligned}
& I M R=3.072+0.075 P O V+0.083 \text { SMOKERS }+0.075 \text { BLACK } \\
& \text { (3.75) (1.97) (2.50) } \\
& \text { + 0.586 WEST + 1.231 MIDWEST + 0.951 SOUTH } \\
& \text { (1.83) (4.08) (2.57) }
\end{aligned}
$$

where $t$-ratios are in parentheses.

$$
\bar{R}^{2}=.698
$$

The results in general show a strong positive association between poverty rates and infant mortality rates $(p=.056)$. The poor lack access to a consistent source of care and likely use fewer physician services. States with a higher percentage of women who smoke tend to be states with higher infant mortality rates $(p=.016)$. Cigarette smoking can cause serious health problems for women during pregnancy, which manifest themselves in higher infant mortality rates. Infant mortality rates are significantly higher for African Americans than for whites $(p<.001)$ 
All 50 states were divided into four Census regions: West, Midwest, South, and Northeast. After allowing for statewide differences in smokers, poverty rates and race, a regional pattern emerges. States in the Midwest and South have significantly higher infant mortality rates for all races than do states elsewhere. A series of two-sample $t$-tests reveals regional differences between race-specific infant mortality rates. White infant mortality rates are significantly lower in the Northeast compared to states in the West $(p=.0073)$, South $(p<.0001)$, and Midwest $(p=.017)$. Nationwide, the three-year average (1998-2000) infant mortality rate among African American babies is more than twice that among whites (13.9 v. 5.8). These rates among African Americans in Midwestern states are significantly higher than those in either the West $(p=.029)$ or Northeast $(p=.039)$.

Economists and family doctors alike should talk about risk factors and prevention more with patients in the Midwest and South, which have the highest infant mortality rates in the country. 